\title{
MICROEMPREENDEDOR INDIVIDUAL: CARACTERIZAÇÃO DO PERFIL DOS EMPREENDEDORES NO BRASIL
}

\section{INDIVIDUAL MICROEMPREENDEDOR: CHARACTERIZATION OF PROFILE OF ENTREPRENEURS IN BRAZIL}

Recebido: 23/09/2017 - Aprovado: 14/03/2018 - Publicado: 26/06/2018 Processo de Avaliação: Double Blind Review

\author{
Elenice da Silva Moraes ${ }^{1}$ \\ Mestranda em Administração e Desenvolvimento Rural \\ Universidade Federal Rural de Pernambuco - UFRPE \\ elenicemoraes7@gmail.com
}

Milly Lilian de Miranda Oliveira

Mestranda em Administração e Desenvolvimento Rural

Universidade Federal Rural de Pernambuco - UFRPE

milly.lmoliveira@gmail.com

\section{Marcelo da Costa Borba}

Mestre em Administração e Desenvolvimento Rural

Universidade Federal Rural de Pernambuco - UFRPE

marcelodcborba@gmail.com

Telma Lucia de Andrade Lima

Doutora em Engenharia da Produção

Universidade Federal de Pernambuco (UFPE)

tlima.ufrpe@gmail.com

Rodolfo Araujo de Moraes Filho

Doutor em Administração

Institut d'Administration des Entreprises - IAE de Grenoble

Université de, IAE / (UPMF), França.

rodolfoamfilho@yahoo.com.br

\footnotetext{
${ }^{1}$ Autor para correspondência: Universidade Federal Rural de Pernambuco, R. Manuel de Medeiros, s/n - Dois Irmãos, Recife - PE, 52171-900. Brasil.
} 
RESUMO: O presente estudo temcomoobjetivo caracterizar o perfil do microempreendedor individual (MEI), formalizado pelo Programa de Cadastro de MEI, no Brasil, no período de julho de 2009 a junho de 2017. O Microempreendedor Individual é um programa criado por meio da Lei Complementar $n^{\circ}$ 128/2008 para motivar a formalização dos trabalhadores autônomos que não estavam inseridos no mercado de trabalho formal.Os dados foram coletados nos institutos de estatísticas do governo (IBGE, IPEA, Receita Federal). O estudoanalisa o perfil do empreendedor MEIsegundo o Estado ao qual pertence, caracterizando-o por gênero, faixa etária, escolaridade e área de atuação. A análise também apresenta a evolução da quantidade de MEI's a partir da criação do programa. Conclui-se que a exploração do perfil evidenciado pode auxiliar na elaboração de estratégias a fim de captar empreendedores para a formalização institucional dos micros empreendimento.

Palavras-chave: Microempreendedor; Formalização; Empreendedorismo.

ABSTRACT: The present study aims to characterize the profile of the Individual Micro Entrepreneur (IME), formalized by the Mei Cadaster program in Brazil, in the period from July 2009 to June of 2017. The Individual Micro Entrepreneur is a program created through complementary Law $n{ }^{\circ} 128 / 2008$ to motivate the formalization of autonomous workers who were not inserting into the formal lab our market. The data was collecting in government statistics institutes (IBGE, IPEA, and IRs). The study analyzes the entrepreneur MEI's profile according to the state to which it belongs, characterized by gender, age group, schooling and acting area. The analysis also presents the evolution of the quantity of MEI's from the creation of the program. It is concluding that the exploration of the evidenced profile can assist in the elaboration of strategies for the uptake of entrepreneurs for the institutional formalization of the Micros undertaking.

Key word: Micro Entrepreneur; Formalization; Profile; Entrepreneurship.

\section{INTRODUÇÃO}

Atualmente, o empreendedorismo tem sido centro de várias políticas públicas desenvolvidas em vários países e cresce no mundo desde 1990, sendo que atingiu miores proporções nos anos 2000. Isto acarretou na formação de vários empreendimentos, os quais, em sua maioria, são informais. Empreendedores surgem em meio às crises, com novas 
alternativas de empreendimentos no mercado de trabalho, inovadores,buscam no empreendedorismo uma alternativa de rentabilidade socioeconômica (DORNELAS, 2014).

Foi a partir da década de 90,também,que o ensino de empreendedorismo ganhou maior destaque no meio acadêmico. Isso ocorreu devido àsaltas taxas de desemprego entre os jovens naquela época.Para desenvolver habilidades empreendedoras voltadas ao mercado de trabalho, a abertura do mercado para investimentos exterioresfoi uns dos motivos que levou a investir em empreendedorismo no Brasil. Isso adveio da esperança de que o país crescesseeconomicamente (SILVA; MANCEBO; MARINO, 2017).

Diante disso, fez-se necessária a Lei Complementar $n^{\circ} 123 / 2006$, a qual teve por objetivo incentivar a esta categoria de empresários que atualmente se encontra bastante em evidência no cenário brasileiro. Esta lei sofreu importantes ajustes pela Lei Complementar $n^{\circ}$. 127, de 14 de agosto de 2007, e também pela Lei Complementar $\mathrm{n}^{\circ}$ 128, de 19 de dezembro de 2008, conhecida como a "Lei Geral das Microempresas e Empresas de Pequeno Porte".

Nesse sentido, a presente pesquisa teve como objetivo caracterizar o perfil do microempreendedor individual (MEI), formalizados pelo Programa de Cadastro de MEIs, no Brasil, no período de julho de 2009 a junho de 2017. Para responder a tal objetivo, fez-se necessária a seguinte pergunta: Como a formalização impacta no perfil do microempreendedor individual (MEI)? Ressalta-se que,por força da Lei Complementar $\mathrm{n}^{\circ} 128 / 2008$, as regras tributárias e fiscais aplicáveis ao Microempreendedor Individual (MEI) passaram a viger a partir de julho de 2009. Por isso, a análise foi efetuada a partir dessa data.

Este artigo é composto por cinco seções: (i) introdução; (ii) fundamentação teórica, a qual descreve sobre empreendedorismo, microempreendedor individual, Lei complementar 128/2008, caracterização do microempreendedor individual; (iii) metodologia; (iv) resultados obtidos com as amostras; e (v) considerações finais.

\section{REFERENCIAL TEÓRICO}

A fundamentação teórica tem como objetivo efetuar a revisão bibliográfica e abordar conceitos que ajudarão a embasar e compreender os assuntos a serem tratados ao longo do estudo. Este trabalho tem a finalidade de conceituar de forma clara e atualizada os assuntos teóricos sobre empreendedorismo e a formalização do MEI.

\subsection{SURGIMENTO DO CONCEITO DE EMPREENDEDORISMO E SUA EVOLUÇÃO}


O crescimento da economia está voltado para a industrialização, isto é, para a maximização da produçãoque visa o desenvolvimento econômico. Não há dúvida de que a alta tecnologia, composta por computadores, robôs nas industrias, automatização ebiogenéticasão qualitativamente importantes. Ela criam a visão para o espírito empreendedor e a inovação na comunidade, e a receptividade para ambos (DRUCKER, 1987).

O mundo tem passado por várias transformações em curtos períodos de tempo, principalmente no século $\mathrm{XX}$, ao longodo qual foi criada a maioria das inovações que revolucionaram o estilo de vida das populações, geradas por invenções/descobertas de algo inédito ou de uma nova visão na utilização dos produtos existentes(DORNELAS, 2014).

Em meados do século XX, o economista Joseph Schumpeter utilizou a palavra empreendedorismo como sendo, de forma resumida, um conceito no qual se executa uma ação que surgiu a partir de inovações. Nos anos de 1967 e 1970,K. Knight e Peter Drucker,respectivamente, introduziram o conceito de risco ao empreendedorismo, pois, para eles,uma pessoa empreendedora precisa arriscar em algum negócio (OLIVEIRA, 2012).

O crescimento do empreendedorismo no fi acelerado na década de 1990, aumentando, proporcionalmente, a partir dos anos 2000, o que pode ser observado nas ações desenvolvidas relacionadas ao longo desse ano. Dornelas (2014, p.8), lista-se alguns exemplos:

Programas de incubação de empresas e parques tecnológicos; desenvolvimento de currículos integrados que estimulem o empreendedorismo em todos os níveis, da educação fundamental à pós-secundária; programas e incentivos governamentais para promover a inovação e a transferência de tecnologia; subsídios governamentais para criação e desenvolvimento de novas empresas; criação de agências de suporte ao empreendedorismo e à geração de negócios; programas de desburocratização e acesso ao crédito para pequenas empresas; desenvolvimento de instrumentos para fortalecer o reconhecimento da propriedade intelectual, entre outros.

Pode-se dizer que, em todo o mundo, o interesse pelo empreendedorismo se estendeu além das políticas públicas nacionais. Assim, chama a atenção de muitas organizações e entidades multinacionais, a exemplo da Europa, dos Estados Unidos e da Ásia. "Há uma convicção de que o poder econômico dos países depende de seus futuros empresários e da competitividade de seus empreendimentos" (DORNELAS, 2014, p.11).

Conforme Giambiagi e Além (2011), o governo é necessário para guiar, corrigir e complementar o sistema de mercado, pois sozinho o empreendedor não é capaz de exercer todas as funções econômicas. Porém, especificamente--a ocorrência de falhas nas atividades 
de mercado, justifica a presença do Estado, em especial, a assimetria de poder de mercado das empresas que influenciam na competição.

\subsection{EMPREENDEDORISMO NO BRASIL:}

O empreendedorismo no Brasil começou a ganhar vigor e a se desenvolver nos anos 90; Com a abertura do mercado interno para as importações, as empresas nacionais tiveram que se adaptar à modernização e a investir em inovação. Antes disso, o cenário político e o econômico não era favoráveis aos investimentos tecnológicos e inovadores, tendo em vista que o empreendedor não conseguia ajuda e nem informações para dar início ao seu próprio negócio. É importante saber que muitos empreendedores mais ousados, tidos como visionários, atuaram desfavoravelmente em um cenário de grande incerteza, empenhando-se, mesmo sem conhecerem a fundo outros conteúdos da área empresarial, a exemplo, de muitos que contribuíram para o desenvolvimento da economia do país (OLIVEIRA, 2012).

Com a abertura da economia, o governo fez uma série de ajustes no plano econômico, controlou a inflação e regulou a economia. Em pouco tempo o país ganhou estabilidade, realizou planejamento e ganhou respeito perante outros países, tendo como fontes de apoio o SEBRAE (Serviço Brasileiro de Apoio à Micro e Pequenas Empresas) e a SOFTEX (Sociedade Brasileira para Exportação de Software).O SEBRAE atua como suporte aos pequenos empresários brasileiros, com a finalidade de informar e fornecer suporte necessário para a abertura de uma empresa. Por suz vez, a SOFTEX foi criada como suporte às empresas de software para auxiliá-lasna produção nacional, por meio do desenvolvimento de projetos de capacitação em gestão e tecnologia aos empresários de informática(OLIVEIRA, 2012).

Segundo a Global Entrepreneuship Monitor (2016),em 2014, 2015 e 2016, a taxa total de empreendedorismo no Brasil (TTE) foi de 34,4; 39,3\%; e 36,0\% respectivamente, obtendo crescimento de 4,9\% em 2015 em comparaçãoa 2014, no entanto, teve queda de 3,3\% em 2016 em relação a 2015. Estes percentuais estão aplicadosà população de 18 a 64 anos em atividade. Estima-se que 52 milhões de brasileiros em 2016 estavam envolvidos na criação ou manutenção de algum negócio, na condição de empreendedor em estágio inicial ou estabelecido. 
Tabela 1 - Taxas de empreendedorismo segundo o estágio dos empreendimentos

\begin{tabular}{l|c|c|c}
\hline \multirow{2}{*}{ Estágio } & \multicolumn{3}{c}{ Brasil } \\
\cline { 2 - 4 } & $\mathbf{2 0 1 4}$ & $\mathbf{2 0 1 5}$ & $\mathbf{2 0 1 6}$ \\
\hline Iniciais & 17,2 & 21 & 19,6 \\
\hline Nascentes & 3,7 & 6,7 & 6,2 \\
\hline Novos & 13,8 & 14,9 & 14 \\
\hline Estabelecidos & 17,5 & 18,9 & 16,9 \\
\hline Total de empreendedores & 34,4 & 39,3 & 36 \\
\hline
\end{tabular}

Fonte: GEM Brasil, 2016.

Apesar do curto tempo, o Brasil apresenta ações e alternativas de investimento ao empreendedorismo, ao apostarem programas de ensino de empreendedorismo, osquais incentivam a população a empreender e a desenvolver o país. O início da divulgação do empreendedorismo no Brasil se deu por conveniência do governo e sobrevivência de muitos trabalhadores, que perderam seus empregos nas grandes estatais após o processo de privatização. Diante disso, o governo se propõe a fornecer subsídios e possibilidades de contribuir para o desenvolvimento na geração de emprego e renda (OLIVEIRA, 2012).

\subsection{ECONOMIA INFORMAL NO BRASIL;}

$\mathrm{O}$ empreendedorismo informal não surgiupor acaso, considera-se que o aumento do desemprego contribuiu de forma significativa para o avanço desse fenômeno. "O conceito de setor informal aparece como um novo instrumento explicativo para um fenômeno histórico que é a existência de atividades econômicas de baixa produtividade e que se desenvolviam à margem da legislação" (SILVAet al, 2010, p.122). Desse modo, o empreendedorismo informal é caracterizado pela atividade na qual os indivíduos estão atuando por uma questão de sobrevivência ou falta de alternativas que lhes proporcionem condições mais dignas e até mesmo por verem a oportunidade de investir em algo de seu interesse(SILVEIRA; TEIXEIRA, 2011).

No entanto, o número de empreendedores que vivem na informalidade no Brasil ainda é grande, mesmo reconhecendo que os empreendimentos formalizadosse sobressaem aos informais. "Com níveis mais elevados de incertezas, os empresários têm maior necessidade de lidar com os desafios encontrados no seu negócio, e um esforço de um planejamento mais formalizado poderá ajudar a enfrentá-los” (BANGS JÚNIOR, 2002, p. 10). Desse modo, 
podemos considerar que as políticas públicas de incentivo ao empreendimento novo-contribuam para o encorajamento dos pequenos empresários a saírem da informalidade.

O cenário do trabalho informal no Brasil é resultado da conjuntura econômica do país, pois com juros altos o pequeno empreendedor não busca seus direitos na formalidade. Logo, conclui-se que não é desejo do pequeno empreendedor perpetuar-se na informalidade, mas que necessite de menos burocracia. Silveira e Teixeira (2011) relatam que o empreendedor informal está nesta condição porque foi obrigado. Ele está ali para sobreviver; não tem como pagar altos impostos. Se for forçado, pode ir à falência por não conseguir competir no mercado. Neste contexto, pode-se dizer que a criação do MEI - Microempreendedor Individual foi importante para apoiar os novos empreendimentos.

\subsection{MICROEMPREENDEDOR INDIVIDUAL;}

O modelo de previdência social adotado no Brasil é o mesmo desde a sua formação, o qual se mantém voltado aos trabalhadores formais. Segundo Costanzi (2011), "conforme números do Ministério da Previdência Social que apontam que, em 2009, cerca de $80 \%$ dos contribuintes do Regime Geral de Previdência Social eram empregados". Esse modelo é explicado pela configuração do mercado de trabalho nacional e de sua incompatibilidade parcial com o modelo de seguro social, o qual não consegue incluir os trabalhadores desempregados, empregados rurais e urbanos sem carteira, como as demais atividades autônomas (JACCOUD, 2009).

Os chamados trabalhadores por conta própriarespondem por uma parcela relevante da desproteção previdenciária no Brasil, sendo seu nível de proteção inferior até mesmo àquele predominante entre os trabalhadores domésticos. Uma pequena proporção desse grupo contribui para a Previdência Social, prevalecendo alto nível de informalidade nessa posição da ocupação. Em muitos casos, trata-se de alternativa de sobrevivência ou ocupação de última instância para aqueles que não conseguem se inserir no mercado formal (COSTANZI et al., 2011).

Diante dessa realidade, o Governo Federal do Brasil promoveu várias medidas com intuito de ampliar a formalização dos chamados trabalhadores por conta própria: a) a Lei $n^{\circ}$ 10.666/2003, que alterou a sistemática de recolhimento dos trabalhadores autônomos; b) a instituição do Plano Simplificado de Previdência Social (PSPS), por meio da Lei Complementar n $123 / 2006$, que reduziu a alíquota de $20 \%$ sobre o salário de contribuição para $11 \%$ sobre o salário mínimo para contribuintes individuais que prestam serviços para pessoas físicas e 
contribuintes facultativos, com direito apenas a aposentadoria por idade no valor de um salário mínimo (BRASIL, 2006).

A Lei do Microempreendedor, Lei Complementar $n^{\circ} 128$ de 2008, cria a figura do microempreendedor individual, alterando a Lei Geral da Micro e Pequena Empresa (LEI COMPLEMENTAR N¹23 DE 2006). O Microempreendedor individual é definido como o trabalhador autônomo, legalizado como pequeno empresário, faturando até $\mathrm{R} \$ 60.000,00$ (sessenta mil reais) por ano e não tenha sido sócio ou titular de outra empresa anteriormente. Segundo a Legislação Complementar no 123 de 14 de dezembro de 2006:

O microempreendedor Individual - MEI poderá optar pelo recolhimento dos impostos e contribuições abrangidos pelo Simples Nacional em valores fixos mensais, independentemente da receita bruta por ele auferida no mês, na forma prevista neste artigo. $\S 1^{\circ}$ Para os efeitos desta Lei Complementar, considera-se MEI o empresário individual a que se refere o art. 966 da Lei no 10.406, de 10 de janeiro de 2002 (Código Civil), que tenha auferido receita bruta, no anocalendário anterior, de até R $\$ 60.000,00$ (sessenta mil reais), optante pelo Simples Nacional e que não esteja impedido de optar pela sistemática prevista neste artigo. (BRASIl., 2006).

A fim de que os autônomos não formalizados fossem motivados para a formalização, foram oferecidos alguns incentivos incluídos no Código Civil, que abrangem a contabilidade simplificada, baixos valores de arrecadação pelo Governo e dispensa de alguns tributos, como o Imposto de Renda da Pessoa Jurídica.

\section{PROCEDIMENTO METODOLÓGICOS:}

Para elaboração deste estudo, foi utilizada abordagem qualitativa, que historicamente é utilizada em alguns campos específicos de investigação nas ciências sociais, podendo ser em estudosvoltados ao setor público ou por falta de quantidade suficiente a amostras quantitativas.

Para a realização do estudo exploratório - descritivo, as variáveis escolhidas para análise e caracterização do perfil do microempreendedor, a fim de auxiliar na caracterização,compreenderam:UF - estado ao qual os microempreendedores estão vinculados; gênero; ramos de atuação; escolaridade; faixa etária.

O período de recorte dos dados foi de julho de 2009, ano em que foi iniciada a campanha para formalização dos microempreendedores, até junho de 2017.Os dados utilizados para análise compreendem dados primários, obtidos a partir de fonte governamental, o Portal Empreendedor - MEI. Para a análise, foi formada uma série temporal, definida por Gujarati (2011) como um conjunto de observações dos valores que uma variável assume em diferentes 
momentos do tempo, podendo ser coletados a intervalos regulares (diariamente, semanalmente, mensalmente, anualmente). Vale ressaltar que a série temporal trabalhada é caracterizada como estacionária, pelo fato de sua média e variância não variarem sistematicamente ao longo do tempo (GUJARATI, 2011).

$\mathrm{Na}$ análise estatística descritiva, o pesquisador está interessado em descrever um dado fenômeno ou uma realidade. A fim de analisar a série temporal referente aos microempreendedores formalizados, será utilizado o método de análise das variações percentuais, com vistas a analisar a tendência, desconsiderando causas que possam levar às variações. Além deste, será utilizado o método de análise pela média móvel, para identificar se as variáveis apresentam tendências de crescimento e estagnação ou se houve efeitos sazonais ou cíclicos durante o passar do tempo (TERRA; BANDEIRA, 2014).

\section{APRESENTAÇÃO E ANÁLISE DOS RESULTADOS:}

Nesta seção, serão apresentados os resultados da pesquisa, tendo como base de orientação os objetivos traçados. As informações foram apresentadas em subseções específicas, objetivando elucidar o sentido dos dados e das informações levantadas. A partir da base de registros da Receita Federal do Brasil, analisou-se o perfil do microempreendedor individual quanto à data de sua formalização, localidade, gênero, idade e setor econômico.

\section{PERFIL DO MICROEMPREENDEDOR INDIVIDUAL;}

A formalização do MEI teve início em julho de 2009. Desde então, o número de empreendimentos registrados passou a ter intenso crescimento. Isto se deve ao fácil acesso que o empreendedor tem para tornar seu empreendimento formal. De julho de 2009 a 30 de junho de 2017, foram registrados no Brasil mais desete milhões de Microempreendedores Individuais no Brasil, conforme apresenta o Gráfico 1. 
Gráfico 1- Total de microempreendedores individuais (acumulado) - jul./2009 a jun./2017

$1^{\circ}$ semestre 2017

$2^{\circ}$ semestre 2016

$1^{\circ}$ semestre 2016

$2^{\circ}$ semestre 2015

$1^{\mathrm{o}}$ semestre 2015

$2^{\circ}$ semestre 2014

$1^{\circ}$ semestre 2014

$2^{\circ}$ semestre 2013

$1^{\circ}$ semestre 2013

$2^{\circ}$ semestre 2012

$1^{\mathrm{o}}$ semestre 2012

$2^{\circ}$ semestre 2011

$1^{\circ}$ semestre 2011

$2^{\circ}$ semestre 2010

$1^{\mathrm{o}}$ semestre 2010

$2^{\circ}$ semestre 2009

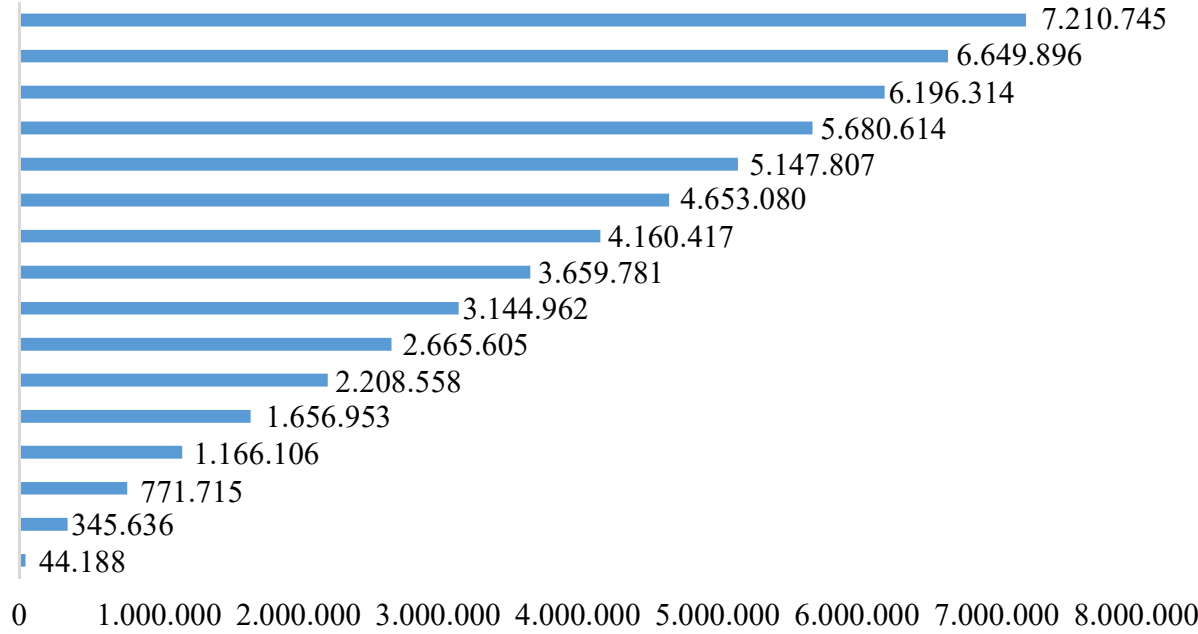

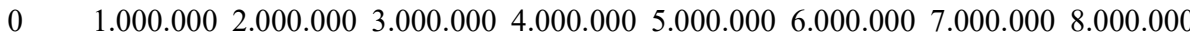

Fonte:Elaboração própria com base de dados da Receita Federal(2017).

De julho de 2009 a junho de 2017, o número de microempreendedores individuais cresceu em uma média de 477.770 por semestre. O $1^{\circ}$ semestre de 2017 foi o de maior saldo já registrado, com 560.849 novos negócios, apresentado no Gráfico 2. Este fenômeno pode ter ocorrido em razão da crise que o país enfrenta nos últimos anos. Esse número foi 1,6\% maior que o $2^{\circ}$ semestre de $2012,551.605$ e $5 \%$ maior que o $2^{\circ}$ semestre de $2015,532.807$.Até junho de 2017, o mês com maior saldo de novos MEI's foi o de dezembro de 2010, com 123.086 novos negócios.

Gráfico 2 - Saldo Semestral de microempreendedores individuais jul/2009 a jun/2011

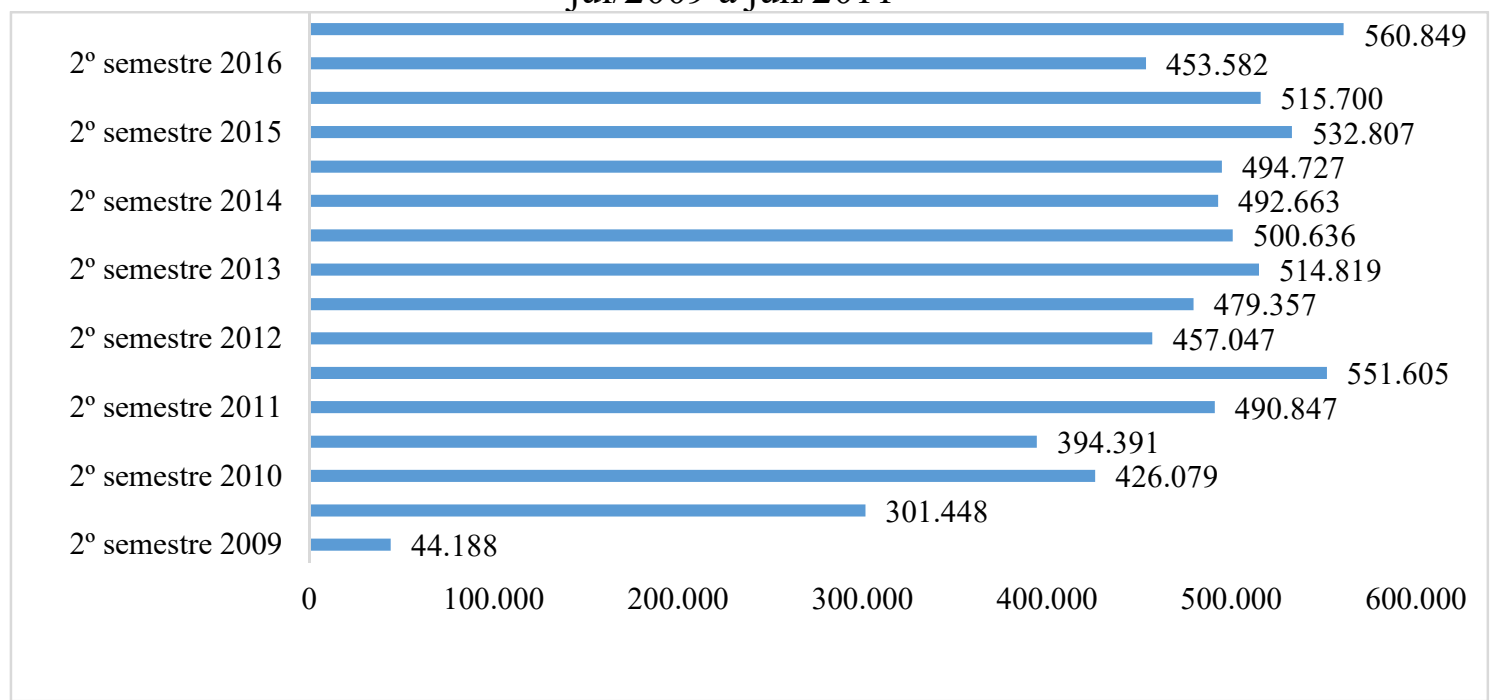

Fonte:Elaboração própria com base de dados da Receita Federal(2017) 
De acordo com o SEBRAE (2015), o IBGE define o trabalhador por conta própria- como uma pessoa que trabalha em seu próprio empreendimento, sozinha ou com sócio, sem ter empregado, podendo contar, ou não, com o auxíliode familiares. Portanto, como a maioria dos MEIs não têm empregados, a quase totalidade dos MEIs seria classificada como trabalhador, segundo o IBGE.Esses os trabalhadores não têm CNPJ e nem sócios, logo são há significativas possibilidade de tornarem MEI em alguns anos.

A Tabela 2 apresenta a distribuição do número de MEI e seu crescimento de dezembro de 2010 a dezembro de 2016, por Unidade da Federação (UF). Assim como em 2016, os anos anteriores também indicam maiores números do MEI em cinco estados, São Paulo (1.711.010), Rio de Janeiro (816.607), Minas Gerais (729.746), Bahia (395.692) e Rio Grande do Sul (389.857). As cinco UF respondem, sozinhas, por 60,9\% de todos os microempreendedores individuais do Brasil nos últimos anos. 
Tabela 2 - Número de MEI, participação e crescimento, por UF - dez/2010 a dez/2016

\begin{tabular}{|c|c|c|c|c|c|c|c|c|}
\hline UF & $\begin{array}{c}\text { Número de } \\
\text { MEI em } \\
\text { dez/10 }\end{array}$ & $\begin{array}{c}\text { Número de } \\
\text { MEI em } \\
\text { dez/11 }\end{array}$ & \begin{tabular}{|c} 
Número de \\
MEI em \\
dez/12
\end{tabular} & $\begin{array}{c}\text { Número de } \\
\text { MEI em } \\
\text { dez/13 }\end{array}$ & $\begin{array}{c}\text { Número de } \\
\text { MEI em } \\
\text { dez/14 }\end{array}$ & $\begin{array}{c}\text { Número de } \\
\text { MEI em } \\
\text { dez/15 }\end{array}$ & $\begin{array}{c}\text { Número de } \\
\text { MEI em } \\
\text { dez/16 }\end{array}$ & $\begin{array}{c}\text { Participaçã } \\
\text { o e m } \\
\text { dez } / 16\end{array}$ \\
\hline $\mathrm{AC}$ & 2.745 & 6.472 & 9.168 & 11.484 & 13.190 & 14.852 & 16.282 & $0,20 \%$ \\
\hline $\mathbf{A L}$ & 8.589 & 22.135 & 35.600 & 46.234 & 55.724 & 65.483 & 73.285 & $1,10 \%$ \\
\hline $\mathbf{A M}$ & 9.154 & 19.036 & 28.954 & 37.520 & 45.191 & 53.734 & 60.827 & $0,90 \%$ \\
\hline $\mathbf{A P}$ & 2.302 & 5.814 & 7.793 & 9.242 & 10.541 & 12.170 & 13.740 & $0,20 \%$ \\
\hline BA & 53.599 & 133.949 & 192.924 & 246.910 & 300.160 & 352.440 & 395.692 & $6,00 \%$ \\
\hline $\mathrm{CE}$ & 17.284 & 48.252 & 82.968 & 120.362 & 154.800 & 188.008 & 215.198 & $3,20 \%$ \\
\hline DF & 13.034 & 31.023 & 50.815 & 68.614 & 86.980 & 107.077 & 123.769 & $1,90 \%$ \\
\hline ES & 17.170 & 42.656 & 68.806 & 95.023 & 121.839 & 148.740 & 174.250 & $2,60 \%$ \\
\hline GO & 25.861 & 61.629 & 98.644 & 138.517 & 175.241 & 208.403 & 238.150 & $3,60 \%$ \\
\hline MA & 9.647 & 25.175 & 37.778 & 51.492 & 65.464 & 79.093 & 89.430 & $1,30 \%$ \\
\hline MG & 63.171 & 163.027 & 274.550 & 388.497 & 502.724 & 620.101 & 729.746 & $11,00 \%$ \\
\hline MS & 13.012 & 27.876 & 42.906 & 56.252 & 69.707 & 82.517 & 95.890 & $1,40 \%$ \\
\hline MT & 13.222 & 33.781 & 52.718 & 71.795 & 88.891 & 105.912 & 121.633 & $1,80 \%$ \\
\hline $\mathbf{P A}$ & 16.207 & 45.275 & 73.485 & 97.730 & 120.388 & 142.739 & 163.375 & $2,50 \%$ \\
\hline PB & 9.431 & 22.863 & 36.950 & 49.715 & 64.729 & 78.989 & 92.606 & $1,40 \%$ \\
\hline $\mathbf{P E}$ & 23.887 & 58.437 & 91.316 & 124.313 & 156.829 & 189.536 & 217.606 & $3,30 \%$ \\
\hline PI & 4.534 & 13.904 & 23.339 & 32.269 & 40.501 & 49.745 & 56.992 & $0,90 \%$ \\
\hline PR & 34.706 & 83.396 & 136.848 & 193.670 & 252.646 & 315.556 & 376.750 & $5,70 \%$ \\
\hline RJ & 88.153 & 213.280 & 327.206 & 438.478 & 555.851 & 690.106 & 816.607 & $12,30 \%$ \\
\hline $\mathbf{R N}$ & 8.518 & 23.730 & 37.204 & 50.133 & 62.511 & 76.264 & 88.161 & $1,30 \%$ \\
\hline RO & 5.649 & 13.821 & 21.320 & 27.760 & 33.135 & 38.258 & 43.300 & $0,70 \%$ \\
\hline $\mathbf{R R}$ & 1.471 & 3.785 & 5.815 & 7.707 & 9.145 & 10.637 & 11.726 & $0,20 \%$ \\
\hline RS & 36.550 & 90.897 & 152.152 & 212.350 & 269.988 & 329.987 & 389.857 & $5,90 \%$ \\
\hline SC & 21.880 & 52.536 & 88.155 & 123.861 & 159.682 & 199.555 & 241.262 & $3,60 \%$ \\
\hline $\mathbf{S E}$ & 4.984 & 12.745 & 19.268 & 24.926 & 30.741 & 36.918 & 42.574 & $0,60 \%$ \\
\hline SP & 135.455 & 386.160 & 647.064 & 905.043 & 1.169 .225 & 1.439 .272 & 1.711 .010 & $25,70 \%$ \\
\hline TO & 8.414 & 15.299 & 21.859 & 29.884 & 37.257 & 44.522 & 50.178 & $0,80 \%$ \\
\hline Total Geral & 771.715 & 1.656 .953 & 2.665 .605 & 3.659 .781 & 4.653 .080 & 5.680 .614 & 6.649 .896 & $100 \%$ \\
\hline
\end{tabular}

Fonte: Elaboração própria com base de dados da Receita Federal, 2017.

Pode-se ver, no Gráfico 3, que nas regiões mais populosas a concentração dos contribuintes do MEI são as maiores. A região que mais concentra microempreendedores individuais é o Sudeste $(51,6 \%)$, seguida do Nordeste $(19,1 \%)$, Sul $(15,2 \%)$, Centro-Oeste $(8,7 \%)$ e Norte $(5,4 \%)$. Apesar de um movimento bastante gradual, as regiões Sudeste e Sul têm aumentado sua participação, enquanto que as restantes registram pequena queda na sua contribuição para a totalidade do MEI. Isto não implica numa redução das demais regiões, mas um interesse maior das regiões sul e sudeste em formalizar os empreendimentos.

REMIPE- Revista de Micro e Pequenas Empresas e Empreendedorismo da Fatec Osasco V. 4, N¹, jan.-jun. 2018. 
Gráfico 3 - Distribuição do total de MEI, por região - 2011 a 2016

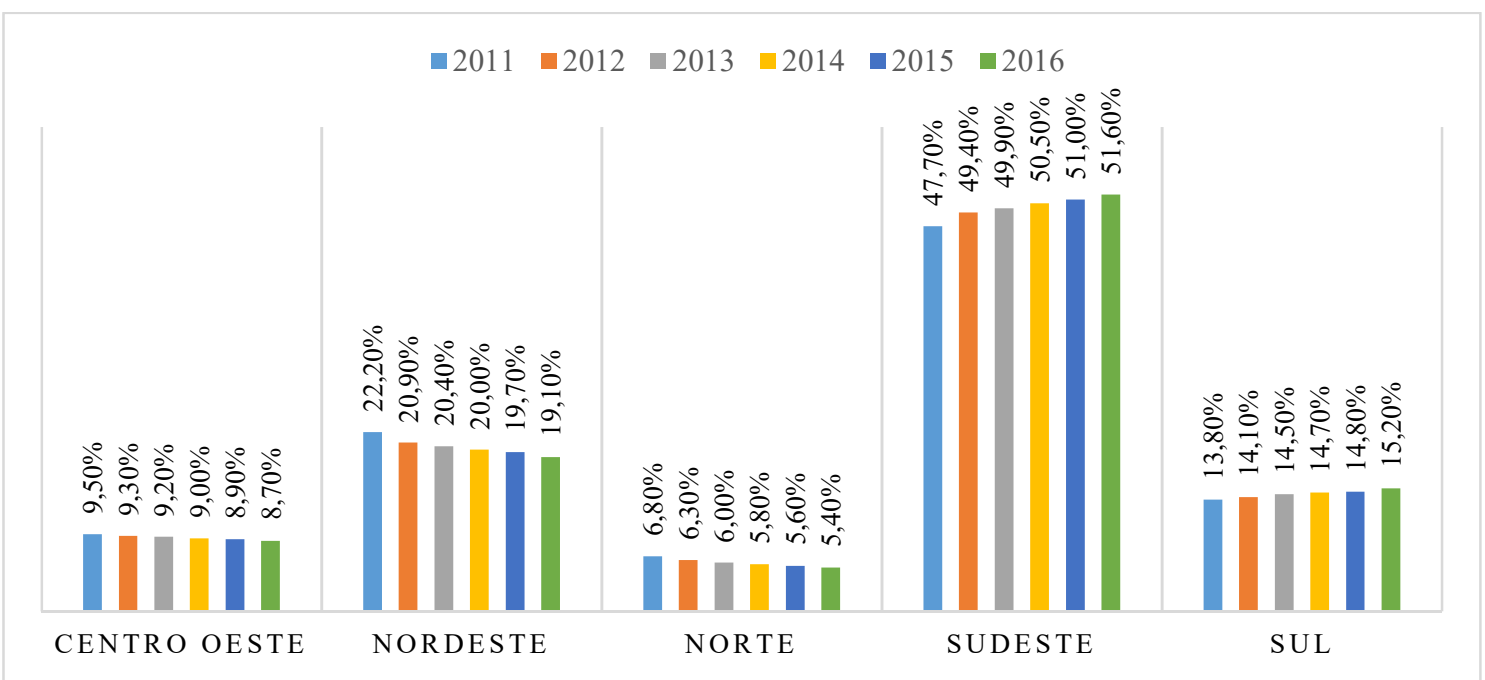

Fonte: Elaboração própria com base de dados da SEBRAE, 2017.

Dos registrados no MEI no Brasil, 52,4\% são do sexo masculino e 47,6\% do gênero feminino, conforme apresenta-se no Gráfico 4. O percentual de mulheres entre os microempreendedores individuais apresentou um leve aumento de 2010 a 2016.

Gráfico 4 - Distribuição de MEI por gênero - 2010 a 2016

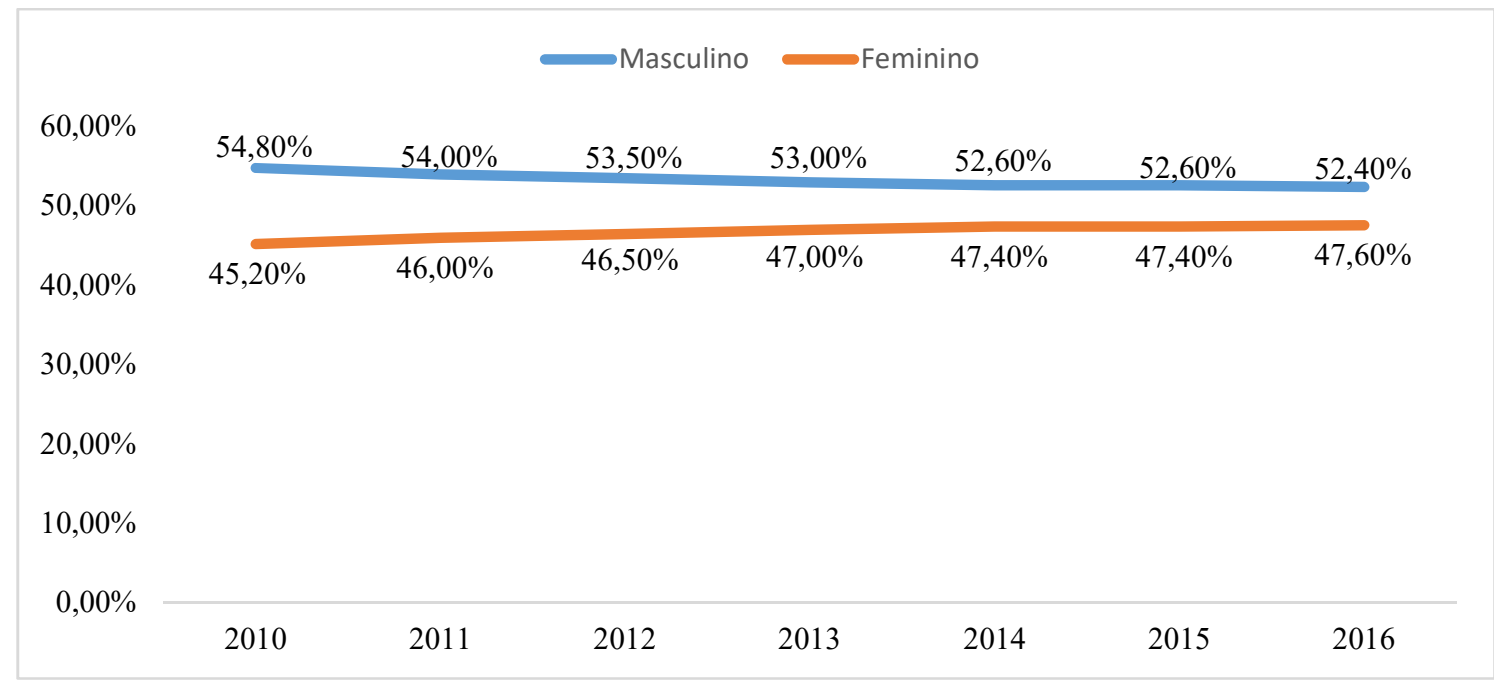

Fonte: SEBRAE, 2015.

A distribuição por gênero varia entre os diferentes setores do ramo de trabalho. Como apresentado no gráfico 5, as mulheres são maioria entre os microempreendedores individuais da indústria (55\%), serviços (52\%) e comércio (51\%). Em compensação, os homens são quase 
a totalidade dos MEI da construção civil (94\%) e constituem considerável maioria dos microempreendedores da agropecuária (82\%), que são atividades em geral comuns aos homens, porém mesmo sendo pequena a porcentagem entre as mulheres, muitas vezes, desempenham um trabalho de qualidade no setor.Os microempreendedores individuais do sexo masculino dividem-se em $49 \%$ no setor de comércio, $48 \%$ no setor de serviços, $94 \%$ na construção civil, $46 \%$ na indústria e $82 \%$ na agropecuária.

Gráfico 5 - Distribuição de MEI por sexo dentro dos setores, em dezembro de 2016

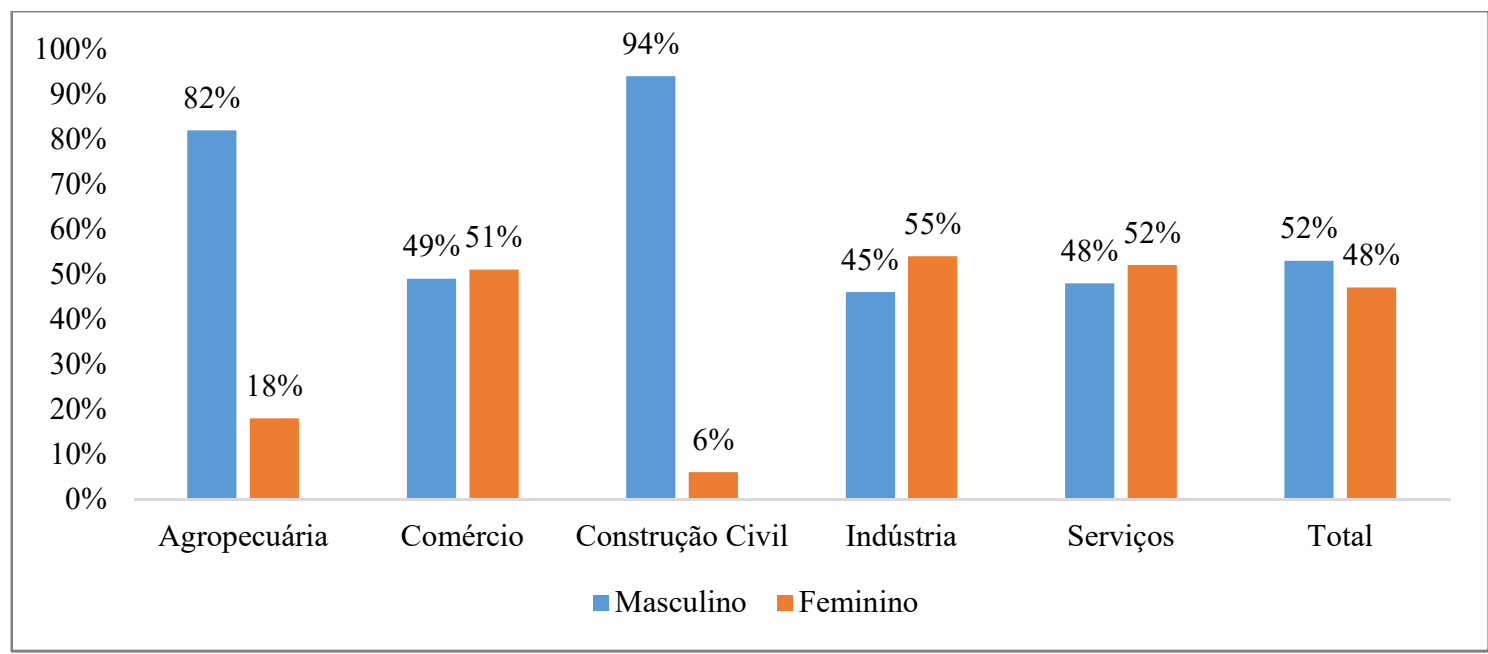

Fonte: SEBRAE (2015).

Ao longo dos anos,a tendência à procura pelo programa do MEI é de pessoas mais idosas, inclusive aposentadas, pois a média de idade do MEI em 2015 era de 38,2 anos, versus 37,3 anos em 2013. A faixa etária com maior concentração de MEI é a de 30 a 39 anos, que responde por 32,9\% (32,9\% em 2013) desses microempreendedores (ver Gráfico 6). A segunda faixa etária mais expressiva é a de 40 a 49 anos, com 23,7\% dos empreendedores, seguida pelas faixas etárias de 50 a 64 anos e de 25 a 29 anos com 16,4\% e 15,1\%, respectivamente. 
Gráfico 6 - Distribuição de MEI por faixa etária - 2013, 2015 e 2016.

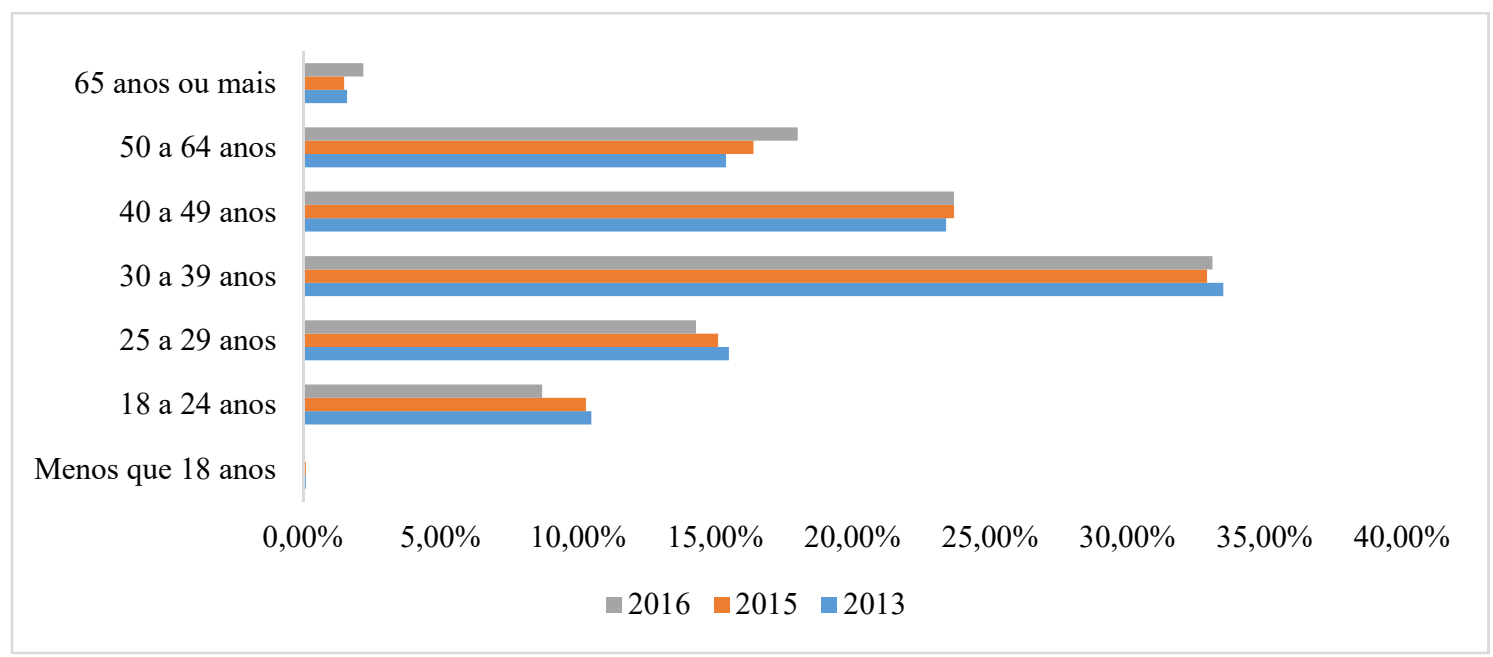

Fonte: SEBRAE(2017).

Ao analisar a escolaridade dos microempreendedores individuais, percebe-se que a maioria tem nível médio completo (32\%). Observando mais detalhadamente, temos: $1 \%$ sem instrução formal; $16 \%$ com fundamental incompleto; $8 \%$ com fundamental completo; $9 \%$ com médio incompleto; $32 \%$ com ensino médio completo; $0,4 \%$ com técnico incompleto; $2 \%$ com técnico completo; $9 \%$ com superior incompleto; $20 \%$ com superior completo e $4 \%$ com pósgraduação, ver Gráfico7.

Gráfico 7 - Escolaridade MEI - Detalhado

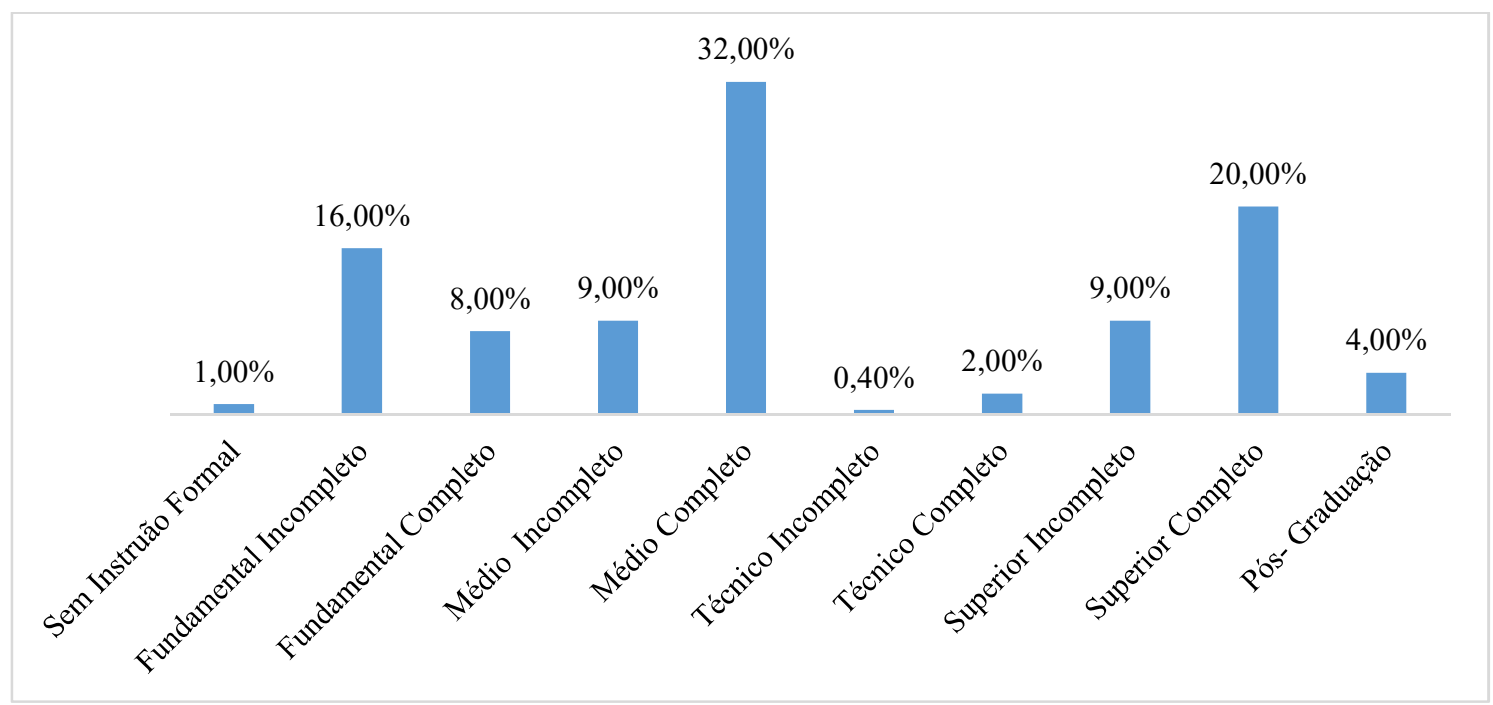

Fonte: SEBRAE (2017). 
Ao se observar a evolução dessa variável, percebe-se um movimento interessante. No período de 2011 a 2016, diminuiu a participação do nível intermediário de escolaridade (ensino médio ou técnico completo). Em compensação, aumenta a participação dos níveis extremos de escolaridade, principalmente os mais elevados. De 2012 a 2016, a proporção de microempreendedores individuais com ensino superior incompleto aumentou gradativamente.No ano de 2014 não foram divulgados os dados sobre os níveis de escolaridade.

Pode-se perceber que o perfil do microempreendedor individual, reflete crescimento de todos os setores da economia, isso conjectura para a formalização de novos empreendimentos formais no Brasil. Os Estados que mais investem no MEI são os que apresentam maiores índices populacionais do país.

\section{CONSIDERAÇÕES FINAIS:}

O presente artigo objetivou traçar o perfil do microempreendedor individual (MEI), formalizado pelo Programa de Cadastro de MEIs, no período de julho de 2009 a junho de 2017. O resultado demonstrou que a média de crescimento por semestre está aumentando consideravelmente em torno de 477.770, com maiores incrementosnos anos de 2010 para 2011, com 22\% de aumento no número de microempreendedores e de 2011 para 2012, com aumentopara $14 \%$ na quantidade de empreendedores formalizados.

Além dessesdados, pode-se perceber que a formalização do microempreendedor individual foi importante para o crescimento da renda e benefícios dos trabalhadores que atuavam informalmente. Estes dados refletem a consciência para formalização dos microempreendedores brasileiros, a visualização de benefícios e a preocupação com o futuro das pessoas que querem montar seus negócios, que, com a antiga forma burocrática para se abrir uma empresa, era difícil iniciar um novo negócio.Os maiores estados com microempreendedores individuais se mantiveram no intervalo temporal analisado. Entretanto, o maior incremento no decorrer do período foi do Estado de São Paulo, enquanto os demais estados com os maiores números de contribuintes- se mantiveram estáveis.

Dentro deste contexto, ainda vale destacar a participação feminina entre os MEIs. Apesar de não serem maioria, as mulheres são destaque nos setores de comércio, indústria e serviços, ainda que correspondendo a 47,6\% dos empreendedores. Ressalta-se também,-que a faixa etária predominante dos investidores foram de 30 a 39 anos. Dessa maneira, fica evidenciado que, quando o indivíduo termina os estudos, seja ele médio ou superior, possui um interesse maior em investir no MEI, mesmo que as outras escolaridades mostrem um 
crescimento relevante nos últimos anos.Nessa conjuntura destaca-se ainda que o MEI com nível médio completo,ou superior,possui maior destaque entre os investidores, com $52 \%$ dos empreendedores. Isso pode estar interligado ao nível de formação, pois ao terminar um curso, nível médio ou superior, a pessoa busca entrar no mercado de trabalho, portanto, uma das alternativas é investir em seu próprio negócio.

Ao conhecer o perfil dos MEIs brasileiros, fica realizável a elaboração de políticas públicas e estratégias que influenciem trabalhadores por conta própria à formalização, e surgem novas possibilidades de estudo, como o perfil por estado, analisando minuciosamente os ramos de atuação, pontos fortes e fracos do microempreendedor da região, oportunidades para motivar a formalização e modelos de gestão destes empreendedores.

Em virtude da utilização dos dados secundários, houve a limitação para aprofundamento, no tratamento dos dados e especificaçãodas informações para busca de correlações de variáveis e progressão da análise, como a satisfação dos microempreendedores individuais têm em relação ao programa proposto pelo Governo Federal do Brasil.

\section{REFERÊNCIAS:}

BANDEIRA, M. Análise de dados, cronograma, orçamento, pertinência e considerações éticas. Universidade Federal de São João Del Rei. 2012. Departamento de Psicologia. Disponível em: <http://www.ufsj.edu.br/portal-repositorio/File/lapsam/Texto-10-ANALISE\%20DE\%20DADOS.pdf> Acesso em: 03 jul. 2017.

BANGS JUNIOR, David H. Plano de Negócio: criando um plano para seu negócio ser bemsucedido. São Paulo: Nobel, 2002.

BRASIL. Lei Complementar $n^{0}$ 123, DE 14 de dezembro de 2006. Institui o Estatuto Nacional da Microempresa e da Empresa de Pequeno Porte. Disponível em: $<$ http://www.planalto.gov.br/ccivil_03/leis/LCP/Lcp123.htm> Acesso em 28 jun. 2017.

CASTELLIS, Manuel. A Sociedade em Rede. São Paulo: Paz e Terra, 2009.

DORNELAS, J. C. A., Empreendedorismo: transformando ideias em negócios. $5^{\text {a }}$ ed. Rio de Janeiro: Empreende / LTC, 2014.

DRUCKER, P. F. Inovação e espírito empreendedor (entrepreneurship): prática e princípios. Tradução de Carlos Malferrari. 2a ed. São Paulo: Pioneira, 1987.

DUARTE, F. V. GESTÃO DE SI E EMPREENDEDORISMO: O Microempreendedor Individual e as novas formas de inserção no mercado de trabalho. Trabalho de conclusão de curso (Bacharelado em Ciências Sociais). Universidade Federal do Rio Grande do Sul. Porto 
Alegre - $\quad$ RS. 48f. 2011. Disponível em: $<$ https://www.lume.ufrgs.br/bitstream/handle/10183/78243/000899810.pdf?sequence=1>Aces so em 23 jun. 2017.

GEM. Empreendedorismo no Brasil 2015: Global Emtrepreneuship Monitor - GEM. 2015. Disponível em:

$<\mathrm{Http} / / /$ www.bibliotecas.sebrae.com.br/chronus/arquivos_chronus/bds/bds.nsf/c6de907fe057 4c8ccb36328e24b2412e/\$File/5904.pdf> Acesso em: 26 mai. 2017.

GEM. Empreendedorismo no Brasil 2016: Global Emtrepreneuship Monitor - GEM. 2016. Disponível em:

<http://www.bibliotecas.sebrae.com.br/chronus/ARQUIVOS_CHRONUS/bds/bds.nsf/941a51 dd04d5e55430088db11a262802/\$File/7592.pdf> Acesso em: 26 mai. 2017.

GERHARDT, T. E. SILVEIRA, D. T. Métodos de Pesquisa. Porto Alegre: Editora da UFRGS, 2009. Disponível em: < http://www.ufrgs.br/cursopgdr/downloadsSerie/derad005.pdf $>$ Acesso em 23 jun. 2017.

GIAMBIAGI, F.; ALÉM, A. C. Finanças Públicas: teoria e prática no Brasil. 4. ed. Rio de Janeiro: Elsevier, 2011, 498p.

GIL, A. C. Métodos e técnicas de pesquisa social. São Paulo: Atlas, 2008.

GUJARATI, D. N. PORTER. D.C. Econometria básica. 5 ed. São Paulo: Mac Graw Hill, 2011.

JACCOUD, L. Pobres, Pobreza e Cidadania: os desafios recentes da proteção social. Textopara Discussão, Série Seguridade Social, IPEA, Brasília, n. 1.372, 2009.

OLIVEIRA, F. M. Empreendedorismo:teoria e prática.Especialize On line, 2012. Disponível em: <https://www.ipog.edu.br/revista-especialize-online/edicao-n3-2012/empreendedorismoteoria-e-pratica/> Acesso em 23 jun. 2017.

RANGEL, L. A. et al.Conquistas, Desafios e Perspectivas da Previdência Social no Brasil Vinte Anos Após a Promulgação da Constituição Federal de 1988. Políticas Sociais: acompanhamento e análise - Vinte Anos da Constituição Federal, IPEA, Brasília, v. 1, n. 17, p. $58,2009$.

SEBRAE. Perfil do Microempreendedor Individual: Serviço Brasileiro de Apoio às Micro e Pequenas Empresas - Sebrae. 2011. Disponível em:

$<$ https://m.sebrae.com.br/Sebrae/Portal\%20Sebrae/Estudos\%20e\%20Pesquisas/Perfil\%20Em preendedor\%20Individual\%202011.pdf> Acesso em 10 jun. 2017.

SEBRAE. Perfil do Microempreendedor Individual: Serviço Brasileiro de Apoio às Micro e Pequenas Empresas - Sebrae. 2012. Disponível em:

$<$ https://m.sebrae.com.br/Sebrae/Portal\%20Sebrae/Estudos\%20e\%20Pesquisas/perfil_MEI_2 012.pdf $>$ Acesso em 10 jun. 2017. 
SEBRAE. Perfil do Microempreendedor Individual: Serviço Brasileiro de Apoio às Micro e Pequenas Empresas - Sebrae. 2013. Disponível em:

$<$ https://m.sebrae.com.br/Sebrae/Portal\%20Sebrae/Anexos/Perfil\%20MEI\%202013.PDF> Acesso em 11jun. 2017.

SEBRAE. Perfil do Microempreendedor Individual: Serviço Brasileiro de Apoio às Micro e Pequenas Empresas - Sebrae. 2015. Disponível em:

$<$ https://m.sebrae.com.br/Sebrae/Portal\%20Sebrae/Anexos/Perfil\%20do\%20MEI\%202015.pd f $>$ Acesso em 11jun. 2017.

SEBRAE. Perfil do Microempreendedor Individual: Serviço Brasileiro de Apoio às Micro e Pequenas Empresas - Sebrae. 2017. Disponível em: $<$ http://datasebrae.com.br/wpcontent/uploads/2017/08/Perfil-do-Microempreendedor-Individual_2017-v8.pdf $>$ Acesso em 12jun. 2017.

SILVA, A. B.; LOPES, J. E. G.; RIBEIRO FILHO, J. F.; PEDERNEIRAS, M. M. M. Um estudo sobre a percepção dos empreendedores individuais da cidade de Recife quanto à adesão a Lei do Microempreendedor Individual (Lei MEI-128/08). Revista da Micro e Pequena Empresa, v. 4, n. 3, p. 121-137, 2010.

SILVA, F. C.; MANCEBO, R. C.; MARINO, S. R. H. Educação Empreendedora como Método: o caso do Minor em Empreendedorismo e Inovação da UFF. Revista de Empreendedorismo e Gestão de Pequenas Empresas, v.6, n.1, p. 196-216, 2017.

SILVEIRA, Jane Paula; TEIXEIRA, Milton Roberto de Casto. Empreendedor Individual e os Impactos Pós-formalização. Perquirere:Revista do Núcleo Interdisciplinar de Pesquisa e Extensão, Patos de Minas: v. 1, n. 8, pp. 223--252, 2011. Mensal.

TERRA, L. C. Análise de Tendências. Universidade Anhembi Morumbi. 2014. Disponível em: <http://www2.anhembi.br/html/ead01/estatistica_aplic_mercadologia/aula3.pdf $>$ Acesso em 03 jul. 2017. 